\title{
THE IMPACT OF BORDER POLICY EFFECT ON CROSS-BORDER ETHNIC AREAS
}

\author{
Qianlong Bie ${ }^{a}$, Shangyi Zhou ${ }^{\mathrm{b}}$, Cansong $\mathrm{Li}^{\mathrm{c}}$ \\ ${ }^{a}$ Beijing Normal University,China,Beijing,100875,bieqianlonmg@163.com. \\ b* Beijing Normal University,China,Beijing,100875,twizsy@163.com. \\ ${ }^{c}$ Yunnan Normal University,China,Kunming,650500,cansongli@126.com.
}

KEY WORDS: Geographic border, Border effect, cross-border ethnic area, border management policy, Liberalism

\begin{abstract}
:
Boundary effect analysis is related to border policy making in the cross-border ethnic area. The border effect literatures show that geographic boundaries have obvious impacts on economic, social and cultural relations in both sides of a nation border. Particularly in cross-border ethnic areas, each ethnic group has strong internal spatial structure relevance, and the boundary effect is more obvious. However, most of China's border areas are cross-border ethnic areas, each of border issues is unique. Under this perspective, we analyze the border effects of various boundaries can provide basis for formulating border management policies. For small scale of cross-border ethnic minority areas, how to formulate the boundary management policy is a good question to explore. This paper is demonstrated by a study of the impact of border management policies in Dehong Dai and Jingpo Autonomous Prefecture in Yunnan Province at the border area to Burma. The comparative method is used to analysis the border management policies in past 50 decades for the border area of Yunnan Province .This research aims to define trends within border policy and its influences to national security. This paper also examines Wendy Brown's liberal theory of border management policy. We found that it is not suitable for Sino-Burma border area. The conclusion is that the changes or instability of international economic and political situation has more influence to this cross-border ethnic area, and only innovative policy will be effective in cross-border ethnic area. So the border management policies should reflect the change of international context.
\end{abstract}

\section{INTRODUCTION}

Geographic border is a political line between two different political entities. With its unique function, the border has some barrier or intermediary effects on the economic, society and culture between the two neighbouring countries. Boundary divides abutting nations' identity, and trust. Border effect refers to the improvement or rejection of border's existence on politics, economy, culture which leads to a bad flow of information or elements, and a negative effect on both of the countries. Blocking or opening, they have positive and negative effect, and act as powerful "stabilizer" and "filter". The shielding effect means the blocking function of different regions in cross-border contact and spatial interaction. When the border forms, blocking function of space make the bilateral countries more and more different and discontinuous, as well as on political system, spatial cognition, historical culture, language, and economy. Mediating effect has the mediating function, which provide them the opportunity for bilateral countries to communicate and contact, this comes from the continuity and similarity in physical and cultural geography. In cross-border areas, rivers and mountains can be natural boundary lines which cannot be divided, so this make the ethnic groups have similar languages, culture or cultural customs.

The catalytic effect of border policies are indispensable for border effect. Blocking or opening the borders have different effect. In one hand, the government needs to come out of a strict ethnic policies out of security needs, and in this sense, information, substances and people are blocked; On the other hand, to reduce the development gap, guarantee the right to develop and ethnic identity, we needs opening policies. Nowadays, how the preferential policies' effect and what needs to dealt with in the process, and how to optimize border policies, there weren't any systematic and in-depth study. Previous studies analyze it from the economic angle, and accuse that trade is determinant for stabilization and social improvement. While in ethnology, scholars tends to value policies from the development angle. We thought that analysis on border policy should consider border politics, economy, society, ethnics, security as well as identity.

The social and political stabilization in the minority areas of china is a dynamic stabilization in the process of political development, a key element in the social and political stabilization of the whole country Cross border economic development of ethnic minority areas is closely related to national security. Through various management policies, promoting and supporting minority region's economic and social development are of great significance. Despite growing interest in border effect, there are little empirical studies on the how geographic boundary impacts on cross-border ethnic area. In this paper we show the influence of the policy effect on cross-border ethnic area. We firstly analysis border policies' backgrounds and objectives for the entry point, and takes the policy effect as object to analyze the impact on cross-border ethnic areas, provide an objective basis for small-scale management policies making.

\section{LITERATURE REVIEW}

Along with the globalization process, a great number of Political geographers and research institutions began to focus on borders and border area research. Political geography remains a strong and vibrant element of contemporary human geography (Agnew, Mitchell, Toal, 2003), geopolitics and international boundaries. Likewise, in Berg's useful study of sense of geopolitical national identity and border-crossing 


\section{5 - 6 December 2013, Beijing, China}

experiences along the Estonian-Russian boundaries, he makes generalized statements about local borderland population' and borderlands and their border experience.

Heuk Van Houtum creates the need of international border research through the integration process of Europe and he defines border research trend for integrating process in geography aspects. Moreover, he concludes three research paths that is flow path, over-nation path and race path, which are controversy among geography field. He thinks in mainstream, economic geography, border regards a kind of obstacle factor. Obstacle effect makes influence to the accessibility on both sides border flow. The second path refer to integration and cooperation. A lot of research cluster in policy analysis and policy orientation. According to the policy which is measured by this path, instead of becoming buffer region and conservation region, border regions are active space and key region. The third path, some scholars study human border activities of production and reproduction to understand boundaries and significance of methods, including study of human behaviour and the concept of different aspects. In addition, Henk Van Houtum recalled Julian Minghin and Victor Prescotd classics, and defined that research is boundary study of human practice on space differences in the composition and reproduction. He pointed out that current political geography study aims to understand the relationship between territorial sovereignty and identity, which believes that with the political polarization, isolated populations in different countries appeared, and it would show a different identity, social behaviour determines the spatial pattern of boundary effects. The significance of the study on the difference between the boundary of construction and reproduction. Ontology's core view is what the study of boundary is, what epistemological point of view is how we understand boundaries. Minghin and Victor Prescotd's main concern fisheries the boundary position? How can we generate and evolution of the boundary? What is the political consequences of the boundary position? Other major argument is to distinguish between natural and unnatural borders boundaries, however boundary good and bad borders are ignored, and they did not tell borders from moral standpoint. Literature of border study, the most obvious feature is the interdisciplinary research which focuses on the political and social construction of the boundary, imagination, perception and recognition. Anssi Passi pointed out that space border is not only political boundaries, but also the product and separator of ethnic identity and activities between different countries (Newman and Passi, 1998). Passi insisted that borders may exist on a range of scales, and empirical case shows that communication function of boundary is particularly evident. Border and its significance are determined on historical circumstances, they are part of territory production and institutionalization, which has social communication meanings (Newman and Passi,,, 1998). More and more political geographers are becoming more and more interested in border cultural and social significance, which become to process cultural and symbolic significance (Passi, 1996). Current research focuses on the relevance of the border rather than blocking effect. The key point is to understand the boundaries in people's daily lives as well as their perception of the impact of cross-border integration and interaction, and to discuss the national identity on either side of the border, namely to distinguish the role between "us" and "them " (Houtum, 1998 ; Passi,,, 1996). In general, racial science research approach is no longer concerned about the performance of the boundary in space, but the boundary line of social production and reproduction process. Leimgruber thought that the boundary should be regarded as creation of the human or social constructed substances, which is limited to people's perceptions and attitudes (Leimgruber, 1991).

Julian Minghi focus on border study in a long time, and he believes the border is the most obvious phenomenon of political geography, geography boundary landscape studies focused on the border of national, cultural, and political differences and conflict impact (Minghi, 1963). He pointed out that this process requires not only cultural geographers' study participation, but also participation in other social sciences. Because the study itself has transcend the political line, so it need consider spatial interactions and products of the processes. In 1989, Minghi proposed that border research focuses not only on study landscape, it should also be on its latent function, which mainly refers to division of boundaries ethnic, cultural, identity (Minghi, 1989). Results of Houtum stressed on the need for dynamic analysis other than static and dominant functions. Niebuhr points out that analysis on border effect focus on analysis of blocking strength, potential analysis and integration effect. Current border analysis centres on border division while seldom on social form and spatial expression as well as identity. How the border be constructed, how humans construct and reproduce the border according to their own thinking are the key problem. Emphasize on the process and influence of reconstruction and the reproduction of border as well as smuggling, they may be legal from residents' view, however, it threatens the needs of countries. In this sense, we need to analysis it from social and cultural as well as historical levels.

A border based on authority form contradicts with the economic renewal of border. Newly published Walled States, Warning Sovereignty written by politics geographer Wendy Brown, and she focus on discuss the decrease of the study of authority in the context of globalization, showing how the countries been eroded effected on the identity of country through building separated wall. Cons and Sanyal criticized Brown's point. They pointed out that the hypothesis of Brown is wrong, her statement is easily to be inverted in other borders and segregate walls. Cons and Sanyal wrote that, border is a space which has been infiltrated abroad in safety, identity, trade, and territory domain have been concerned by country and nationalism. Harris use the case of Himalayan region showing that not all the place in border region are connected with the global. Some old commercial space in Himalayan region still in the outer, well the other regions are open to the world at the same time. Harries use the describe of border region to emphasize the theory of places and people which have some problem, because both places and people not static, they reflected the change over the world, and keep intimate connection with key node and centre of other places all over the world. Although these results have been proved, in existing papers, the separate of nation contact caused by political border and further reasons behind this.

\section{THE THEORETICAL BACKGROUND OF BORDER MANAGEMENT POLICY}

\subsection{STUDY AREA}

Dehong Dai and Jingpon autonomous prefecture is located at longitude $97 \circ 31^{\prime}-98 \circ 43$ ', latitude $23 \circ 50^{\prime}-25{ }^{\circ} 20^{\prime}$ (Figure1).As one of the 8 Minority Autonomous Prefecture in Yunnan Province, Dehong has more than 26 minority ethnic groups living side by side with the han people. Its south, west and northwest are bordering upon Myanmar. Along the roads linked China and Burma, people can reach some important towns in Myanmar, such as Lashio, Mandalay, Bhamo and Myitkyina. There are five counties in Dehong. Two of which are county-level cities named Ruili City and Mangshi City, the 


\section{5 - 6 December 2013, Beijing, China}

other three counties include Longchuan County, Yingjiang County and Lianghe County. Dehong is a canyon area in the southwestern mountain range, west Gaoligong Mountain. Dehong has a unique geographical advantage. It has four cities beside the border line except Lianghe County. The length of border line in Dehong measures up 503.8 kilometers, accounts for 2.2 percent of China's land border line and 22 percent of the border line between China and Myanmar. Dehong has rich and diverse ethnic and cultural resources. Han people live together with other minorities such as Dai, Jingpo, Lisu, Achang, D'ang and so on. About 49.7percent of the population are minorities. Among them Dai, Jingpo, Achang, D'ang and Lisu are all crossborder ethnic. Because the border line between China and Myanmar was delimited after the establishment of The People's Republic of China and there is no natural barrier blocking, Dehong has a relatively harmonious ethnic relations with Myanmar border areas. Dehong is one of the most friendly and peaceful border ethnic areas of China.

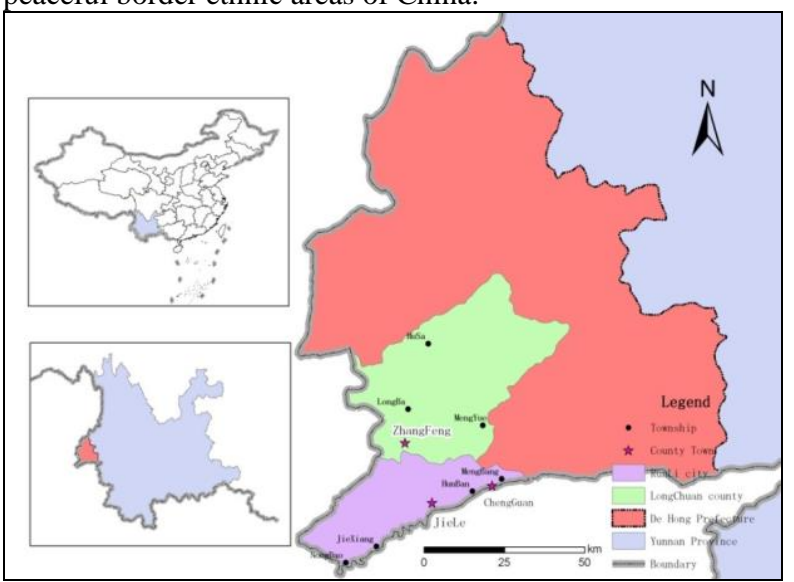

Figure 1. The location of Dehong Dai and Jingpo Autonomous Prefecture

Historically, Dehong was a fortress of the south ancient Silk Road. Now it is the channel entrance of the Burma Road, Stilwell Road and India pipeline, and the intersection of China's economic zone, Southeast Asia economic zone and South Asia economic zone. It is also the best combination of part and the most convenient access that connects China to Southeast Asia, South Asia and the Indian Ocean areas. In 1985 Dehong was constructed as the border trade zone. Government established two national-level ports Wanding, Ruili,two provincial-level ports contains ZhangFeng ports, Yingjiang ports. All the border trade sites in China-Burma border region. Since then Dehong has become the golden port of Southwest China's opening up bridgehead and the forefront of opening up in Yunnan. With the development of economic globalization and regional integration in-depth, China-ASEAN Free Trade Area has been fully completed. The cooperation of Greater Mekong sub-region has promoted further. The economic cooperation between India, Myanmar, Bangladesh and China continue to develop. These have brought great opportunities and challenges to the development and management of the border areas. The ChinaMyanmar border region are particular areas compared with other border regions. First, it is on the Yunnan-Guizhou Plateau with mountains and valleys. Second, land transporting between China and Myanmar must go through this place. Third, it's a complicated cross-border ethnic neighborhood region. These physical and human geographical conditions determines the border management policies of two sides have particularity. The purpose of this paper is to ensure national economic interests, political interests and cultural interests. This article takes Dehong State in the northern section of the China-Burma border area as an example, analyzes the impact of border management policies in different periods on minority areas, and illustrates the different interests of different border management policy.

\subsection{EVOLUTION OF BORDER MANAGEMENT POLICY CHANGES IN CHINA}

Border policies are a series of management laws, regulations and measures legislated by the states. In order to frontier construction, consolidate frontier, defend the sovereignty and territorial integrity, ensure border security and public order, and manage diplomatic affairs. China's border policies consists of specific policies and basic policies. The basic policies are General policy for the safety management affairs and public order management works in border region. The specific policies are series of policies to deal with specific affairs in different. From the subject of policies setting, it include state and local government. It also contain macro policies, medium policies and micro policies in the classification of policy scales. From the content point view, it involve kinds of policies and measures that refer to border trade, cross-border marriage, entry and exit administer.

The border policies in 1949-1978

In this stage, border policies were preliminary formulated in China. At the beginning of the founding of new China, the Chinese government has constructed border management institution implement the border policy. In order to meet the needs of borders and border struggle during this time, the Chinese government has to regulate some principle regulations for border management policy on surrounding countries. The main goals are to develop good-neighborly and friendly relations with proximity countries, ensure the border security. From the 1950 s to 1960 s, the Sino-Soviet border situation became tense. For the sake of border security, the government enact concrete border management measures. The government implemented policies to control the whole borderlines, and focused on critical area in the northeast north and northwest of China, where located at the Sino-Soviet border, China and Mongolia demarcated the border region. The state carried out policies to management dwell people and control institution. These policies are not only used for maintaining border security, but also became the basis of the theories and practices for policies-making in the future. In 1970s, China set many policies in different border region, including the diplomatic principles, ensure border security, maintain border orders, regulation of entry and exit border, emergency treatment of victims, and control cross border. At this stage, it was security between in Sino-Burma. The goal of border policies were maintain border security and consulate the friendship between China and Myanmar.

\section{Border Policies after 1978}

The second stage were steadily management-promoting phase in accordance with the laws. Started in the late 1970s, Chinese government has entered into the new period of the reform and opening up and centered with economic construction, the neighboring environment and relations improvement were clear. The government have gradually adjusted border management policy in border areas. In 1984, the law of the people's republic of china on regional national autonomy have mentioned some border policies. These policies involved some aspects: population mobility, cross-border marriages, and cross-border trade.

Specifically, the three sections border management have turned into administrative management from the military guard. As to the entry and exit, our inhabitants register at the police station in their birthplace. It need for the citizens to be recruited to 


\section{5 - 6 December 2013, Beijing, China}

them, and notify the household registration departments of the places where their permanent residences are. Except the SinoVietnamese border, it gradually carried out opening-up management policy. In the early 1990s, with the continuous development of reform and opening up, and economic construction situation in Yunnan Providence, personnel entry and exit in the three border sections have been intensified. On the basis of the entry and exit management approach and detailed rules for the policy implementation, the government of Yunnan provincial formulated and enacted the local government regulations. The management object is the habitants living on the one side of the Sino-Burmese border, these border residents without formal passport and border pass were prohibited to enter Chinese border regions.

In the matter of Cross border marriage management policies, the China Entry and Exit of Aliens Act stipulates that the foreigners who visited and stayed in China must hold the Chinese government issued identification papers or residence certificates given by the competent authorities, if they resided in China. The foreigners reside in China should submit certificates to the local public security organs within the specified period. In February 17, 1995, the Chinese Ministry of Civil Affairs issued regulations that the inhabitant lived in neighboring border apply for marriage to our dwellers must hold a passport and a valid identity documents, and health certificate etc. The illegal immigrants will not be registered. May be it's a great obstacle to the illegal immigration.

Next, we will review the Border trade policy. Since 1991, the relevant government departments have introduced series incentives polices on border trade. The port area can also enjoy tax breaks policy. When the policy are due to expire at the end of 1995, the amount of cross-border trade in Dehong state with India, Myanmar and Vietnam were significantly reduced. Subsequently, The State Council made a new border tax policy and delay it to2012 until the other new policy making.

\section{METHODS}

\subsection{EVALUATION METHODS}

Regional policy effects refers to the outputs, results and impacts generated by regional policy. Outputs can be reflected by available physical product or value index, the results reflected by change of behaviour, ability or performance of the impact. For quantitative research policy, mostly against implementation results for policy, and the quantitative methods can be classified into comparative analysis, cost method and econometric model. Before and after comparison method is a basic method of policy analysis, usually used for policy implementation or process evaluation and post evaluation. Most abroad study on the policy evaluation is mainly empirical research based on the data obtained, and established perfect index database. The level of policy effect manifested in whether the object has achieved, as well as the degree of realization. If we want evaluate the border management policy, we need to compare the expected target and the actual results. However, the effect of border management policy cannot be reflected from the policy objectives, so we need to take other certain index into account. Then, according to the policy effect evaluation framework (Figure 2), we use comparative analysis methods to evaluate target and effect. If the gap between the effect and target, the policy effect is obvious, if less than 0 , the policy effect is not obvious.

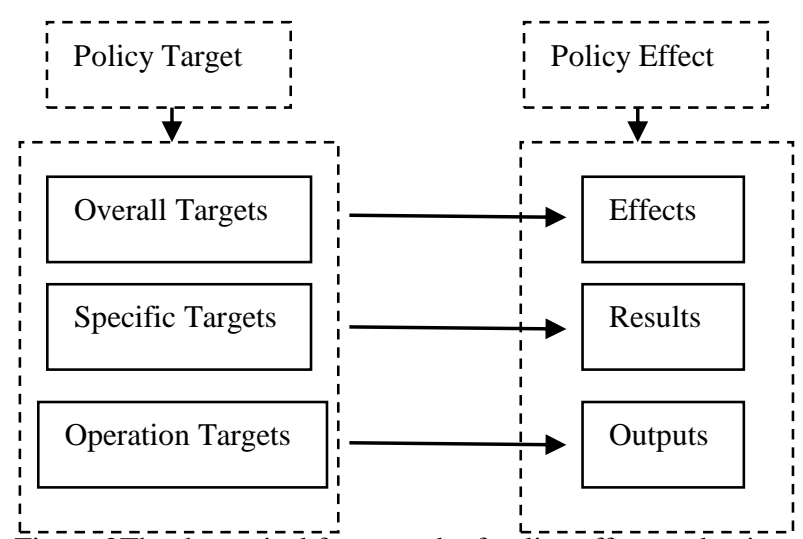

Figure 2 The theoretical framework of policy effect evaluation

Therefore, this paper focuses on the border management policies of people flow and border trade to analyze the border policy effects according to the comparison of comparative management policy objectives and implementation effect. As we can see in the Figure 3, the assessment procedures include policy analysis background, understanding policy process, policy commitment review (issues, targets), policy instrument scan (effectiveness), and policy gap and coherence analysis. At last, this paper evaluate the effect and influence of border management policy in the minority areas.

Currently, the implementation of the China-Burma border region border management policies focused on population movements, cross-border marriages and border trade. Evaluation of the technical route is in accordance with Table 1, the analysis of the policy effects are shown in it.

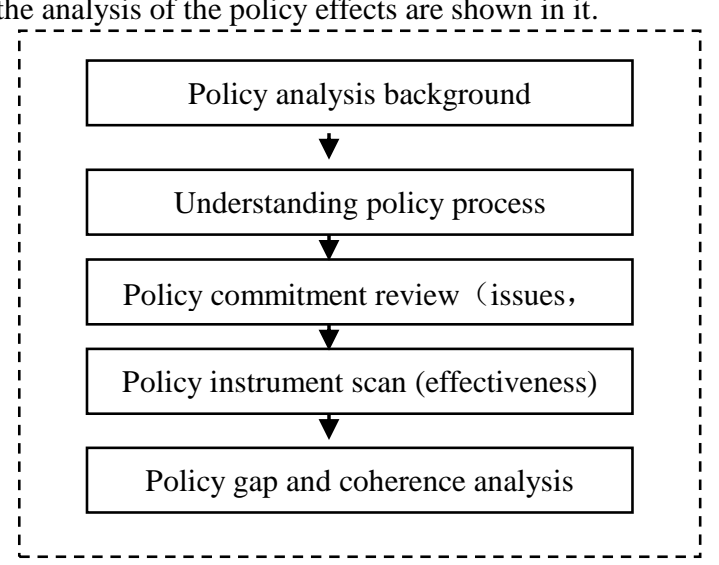

Figure 3The theoretical framework of policy effect evaluation Intent and effect of Population Mobility Policy

In recently years, transnational population movements along Sino-Burma border areas are becoming more and more frequent. The flow types contains trade flow, tourist flow, service flow and illegal flow. The policy effect is characterized as effectively managed on cross-border population movements, prevent the illegal entry, and safeguard national security.

Intent and effect of Cross-border Marriages Policy

The serious problems with the Cross-border Marriages has manifested itself in three aspects. Firstly, it face social management trouble, especially it hard to carry out the family planning work in ethnic areas, and hard to prevent AIDS and smuggling. Some brides from Burmese married in Dehong, but without a Hukou. Then, their social rights and children's education and employment are limited. Up to 2012, a total of registered immigrants intermarry from Burma reach to 9,412, aas well as intermarriage childbearing 9,485. So,the policy effects embody as it can effectively limit the illegal cross-border 


\section{5 - 6 December 2013, Beijing, China}

marriages, maintaining relatively stable ethnic relations on both sides of the border

\section{Intent and effect of Cross-border Trade Policy}

All statistics from Dehong border trade in recently years support this view that the preferential policies have guaranteed the rapid development. The detailed rules formulated by State on 162 imports products from Myanmar enjoy tax rebates, which contribute to maintain formed Myanmar-China industrial trade patterns. So China can afford low-grade industrial products to exchange Burmese resources. In recent years, Sino-Burmese border trade policies of both sides increasingly tight, recovery tariffs and higher tax rates, active or passive import and export quotas, and a variety of non-tariff barriers between the two countries. In general, the policy has promoted cross-border trade orderly on both sides of the border, and regional economic development complement each other, maintain a good relations between countries and regions.

\begin{tabular}{|l|l|l|l|}
\hline $\begin{array}{l}\text { Policy } \\
\text { Content }\end{array}$ & $\begin{array}{l}\text { Population } \\
\text { Mobility }\end{array}$ & $\begin{array}{l}\text { Cross-border } \\
\text { Marriages }\end{array}$ & $\begin{array}{l}\text { Cross-border } \\
\text { Trade }\end{array}$ \\
\hline $\begin{array}{l}\text { Policy } \\
\text { Cognition }\end{array}$ & $\begin{array}{l}\text { Limit } \\
\text { population } \\
\text { mobility }\end{array}$ & $\begin{array}{l}\text { Limit cross- } \\
\text { border } \\
\text { marriages }\end{array}$ & $\begin{array}{l}\text { Manage } \\
\text { cross-border } \\
\text { trade }\end{array}$ \\
\hline $\begin{array}{l}\text { Policy } \\
\text { Targets }\end{array}$ & $\begin{array}{l}\text { Limit illegal } \\
\text { entry, } \\
\text { crime } \\
\text { prevention } \\
\text { safeguarding } \\
\text { state security }\end{array}$ & $\begin{array}{l}\text { limit the illegal } \\
\text { marriage, } \\
\text { Using resource } \\
\text { effectively, } \\
\text { prevent human } \\
\text { trafficking }\end{array}$ & $\begin{array}{l}\text { Anti- } \\
\text { smuggling, } \\
\text { convenience } \\
\text { s to the trade } \\
\text { among } \\
\text { border } \\
\text { residents }\end{array}$ \\
\hline $\begin{array}{l}\text { Policy } \\
\text { tation }\end{array}$ & $\begin{array}{l}\text { loose policy } \\
\text {-Strictly } \\
\text { policy- } \\
\text { Appropriate } \\
\text { loose policy }\end{array}$ & $\begin{array}{l}\text { loose policy- } \\
\text { Strictly policy } \\
\text {-standard } \\
\text { policy }\end{array}$ & $\begin{array}{l}\text { loose policy } \\
\text {-Strictly } \\
\text { policy- } \\
\text { Open and }\end{array}$ \\
\hline $\begin{array}{l}\text { Positive } \\
\text { effect }\end{array}$ & $\begin{array}{l}\text { safeguard } \\
\text { security, } \\
\text { and anti- } \\
\text { crime }\end{array}$ & $\begin{array}{l}\text { Partially solve } \\
\text { the problem of } \\
\text { male marriage }\end{array}$ & $\begin{array}{l}\text { Achieve } \\
\text { trade } \\
\text { complement } \\
\text { arities }\end{array}$ \\
\hline $\begin{array}{l}\text { Negative } \\
\text { effect }\end{array}$ & $\begin{array}{l}\text { Hormal the } \\
\text { nultural } \\
\text { interaction }\end{array}$ & $\begin{array}{l}\text { Deepen the } \\
\text { difficulty and } \\
\text { cost of social } \\
\text { governance }\end{array}$ & $\begin{array}{l}\text { Single } \\
\text { channel } \\
\text { limited the } \\
\text { exchange of } \\
\text { goods }\end{array}$ \\
\hline
\end{tabular}

Table1 The Evolution of management policy and policy effect evaluation in Dehong

\subsection{EVALUATION OF BORDER POLICY BASED ON NEOLIBERAL}

Political geographer Wendy Brown stressed the importance of neoliberal border management policies. Brown explains why the weakening the nation-state sovereignty has become weaken. In the past 50 years, the flowed capital, neoliberalism, international organizations and laws have changed dramatically in nations, which lead the state centered sovereignty weakened. The mainly way are through the flow of thought, religion, labor, capital, political movement (Brown, 2010: 63). In this context, Brown attempted to explain why many countries established the border wall and the meaning of the boundary wall. She argued that the boundary wall is considered as a sovereign state expression, and the countries build the wall aims to wake up some on the surface of the sovereign status. It can be used as an effective tool to prevent and filter the unexpected intruder (Brown, 2010: 100).Boundary walls also have creative, it also a kind of construction contribute to establish nation identity.
That's to say, it's imposed on the internal and external difference, which help to separate the boundary between "us" and "they", become a tool to meet national identity and to provide security and protection. She also took some cases, for instance, United States and the Mexico border, Israel and Palestine, India and Bangladesh, Saudi Arabia and Iraq and Yemen. Therefore, we don't need neoliberal border management policies.

Combined with our case study area, this paper present that the cross-border ethnic areas should not blindly implement liberal border management policies. Because this area is not the main channel for the China to associated its economy with the global, so the flow of population and goods has little impaction the national economy, but the social stability of cross-border ethnic areas is very important to national security. Thus, the border management policy evaluation criteria in this area should be as follows: on the one thing, it should maintain basic social networks within nations. On the other thing, it should enhance cross-border ethnic national identity on the basis of crossborder trade and social welfare policies. Based on this two points, we believe that the current border policy allow crossborder exchanges and cross-border marriages can maintain social stability between the cross-border ethnic internal. At present, border trade policies and implementation methods (such as the construction market in my side), making the Jingpo establish a national identity.

\section{CONCLUSION AND DISCUSSION}

Based on a great number of geographical studies hot issues on borders and border regions, and reviewed the evolution border management policies in Dehong Dai and Jingpo Autonomous Prefecture. This paper attempts to establish theoretical framework of border management policy. The Preliminary conclusion are as follows:

Firstly, the cross-border population flows policies have changed from tight to loose, and then to semi-loose, performed the several steps of the process to explore the cross-border population management. Given the current state, it not only can effectively prevent the "three non-immigration officers" but also to keep the social network stability and national security. Secondly, the cross-border marriage policies have undergone from loose to strict state, and then to ease state. Such actions would contribute to resolve the issue of male marriage in China border, maintain the national internal marriage network. Meanwhile, it also help to avoid the social welfare pressure because the false marriage. But there are also some problems are worthy of discuss, although the system of Hukou has been liberalized but lack of innovation. It may be brought many problems, such as on living, traffic, business, workers, account management, social security, children's education and other employment issues for many cross-border marriage and family. Thirdly, the border trade policies have changed from loose to tight, and became standardized and opened. On the whole, it can grasp the mutually benefit principle for the both sides, and promote economic development and social stability in border areas. The three argument proved that these border policies not only enhance the effect of national identity, but also conducive to the stability of border area.

\section{Acknowledgements}

Thanks for the help of the government of Longchuan County in Yunnan Province during our research process. We would like to acknowledge Yapin Chen who shared many experiences of fieldwork in this area. We should also thank Professor Stanley D. Brunn who gave many constructive comments for this paper. 
Thanks to Yang Cheng who found some literatures to our research.

\section{REFERENCES}

David Newman and Annsi Paasi,1998,.Fences and neighbours in the postmodern world: boundary narratives in political geography. Progress in Human Geography, 22, pp186-207. David Newman,2006.The lines that continue to separate us in our borderless world. Progress in Human Geography,2006, 30:143161.

JulianMinghi,1989.TheGeography of Border Landscapes. London and New York: Poutledge.pp1-14.

Just Boedeker,2012. Cross-border trade and identity in the Afghan-Iranian border region. Subverting Borders.pp39-58. Harris,T,2013.Trading places: new economic geographies across Himalayan borderlands. Political Geography.pp2657670.

Henk Van Houtum,2000. An overview of European Georaphical Research on Borders and Border Regions. Journal of Broadlands Studies.4(1),pp47-56.

Henk Van Houtum,2005.The Geopolitics of Borders and Boundaries.Geopolitics,pp672-679.

Jason Cons, Romola Sanyal. Geographies at the margins: Borders in South Asia.Political Geography (In Press,Corrected Proo,Available online 2 July 2013.)

Houtum, H. van and T. van Naerssen ,2002. Bordering, ordering and othering. In: Tijdschrift voor Economische Sociale Geografie, 93(2), pp. 125-136.
Houtum, H. van and Gielis,R. 2006. Elastic Migration: The case of Dutch Short-Distance Transmigrants in Belgium and German Borderlands. In: TESG, 97(2), pp. 195-202.

Harris, C.D. 1993: New European countries andtheir minorities. Social Science Information 14,pp29-47.

Minghi, J. (1963) 'Boundary Studies in Political Geography', Annals of the Association of American Geographers , pp407420.

Niles Hansen,1977.Border regions: A critique of spatial theory and A European case study. The Annals of Regional Science,pp1-14.

Niebuhr,2001. A. Integration effects in border regions: A survey of economic theory and empirical studies. $H W W A$ Discussion Paper,2001.

Annsi Paasi, 1995.AConstructing territories, boundaries andregional identities. In Forsberg, T., editor, Contestedterritory: border disputes at the edge of theformer Soviet empire, Aldershot: Edward Elgar.

Annsi Paasi, A. 1996a. Territories, boundaries and consciousness:the changing geographies of the FinnishRussianborder. Chichester: Wiley.

Annsi Paasi, A. 1997a: Geographical perspectives on Finnishnational identity. GeoJournal 43,pp41-50.

Van der Velde, M and Houtum H. van (2004) De-politicizing labour market indifference and immobility in the European Union. In: Kramsch O. and B. Hooper (eds) Cross-border governance in the $E U$. Routledge

Zhang Keyun,2006.Some basic issues and analysis framework of regional policy program evaluation. Areal research and development, 25(2),pp14-19. 